\title{
Sobre la cuestión de la clasificación del léxico onomatopéyico de la lengua francesa
}

On the issue of onomatopoeia classification in the French language

\section{Valentina N. Vassilieva \\ Kazan Federal University \\ Russian Federation}

\section{Luiza K. Bairamova}

Kazan Federal University

Russian Federation

\section{Olga F. Ostroumova}

Kazan Federal University

Russian Federation

\section{(C) $\underset{\mathrm{BY}}{(\mathrm{NO}} \bigodot_{\mathrm{ND}}$}

Valentina N. Vassilieva: Department of Roman Philology, Kazan Federal University, Russian Federation. | Correo electrónico: elena.pleuchova@mail.ru 


\section{Resumen}

En este artículo se examina el estatus del léxico onomatopéyico de la lengua francesa. Su objetivo es analizar las características distintivas de las onomatopeyas y las interjecciones, así como los enfoques para clasificar el léxico onomatopéyico según el origen de los sonidos o según principios ortográficos. Los autores proponen clasificar el léxico onomatopéyico considerando su productividad, basada en el estudio de las onomatopeyas, dependiendo de si son sonidos producidos por el cuerpo humano, animales domésticos o salvajes, aves, insectos, la naturaleza, electrodomésticos u otros aparatos eléctricos, o sonidos de la vida cotidiana.

Palabras clave: léxico onomatopéyico; clasificación; interjección; onomatopeya; tipos de palabras; categorías gramaticales; principios; métodos de formación de palabras.

\section{Abstract}

The article looks at the status of French onomatopoetic vocabulary. It aims to analyze the features which distinguish between onomatopoetic units and exclamations, as well as the approaches to classifying onomatopoetic vocabulary according to the source of echoism or orthographic peculiarities. The authors propose to classify onomatopoetic vocabulary taking into consideration their productivity, which can be identified by studying onomatopoetic units representing sounds produced by human beings, animals, and birds both domestic and wild, insects, sounds of nature, sounds produced by musical instruments, household appliances, electric accessories along with everyday life sounds.

Keywords: onomatopoetic vocabulary; classification; exclamation; echoing; type of words; parts of speech; principles; methods of word formation. 


\section{Introducción}

\subsection{La onomatopeya en su aspecto histórico}

El término "onomatopeya" tiene un origen griego y designa una creación de palabras. Este término se usa también en el lenguaje poético como recurso estético. En el presente artículo se analiza la onomatopeya como fenómeno lingüístico de formación de palabras en diferentes lenguas. Se trata de palabras onomatopéyicas que se crean de manera fonética, imitando diferentes sonidos y ruidos de la naturaleza, por ejemplo, los gritos de los animales, el funcionamiento de distintos mecanismos, fenómenos naturales como el ruido del viento, el crujido de las ramas de los árboles, el susurro del follaje, etc. No es posible negar la presencia del léxico onomatopéyico en las lenguas. Las onomatopeyas se usan en diferentes ámbitos: en el registro coloquial, en la publicidad, en el folklore infantil, en la prensa (pueden encontrarse onomatopeyas incluso en los titulares de los artículos), en producciones artísticas, en canciones, y abundan especialmente en los cómics. Pero si los objetos y los fenómenos ya tienen una envoltura propia que se expresa en forma de categorías gramaticales, ¿cuál es el papel de las onomatopeyas? Se supone que la finalidad fundamental de las onomatopeyas es la expresividad, la transmisión realista del sonido, que imita al objeto o al fenómeno, el carácter evocador, la elocuencia, y también su capacidad de crear categorías gramaticales.

Las onomatopeyas pueden clasificarse no solo como un fenómeno lingüístico, sino también social, cuyas raíces están muy relacionadas con los problemas de la aparición y la delimitación de las palabras, con las primeras palabras del lenguaje humano. Existe una gran cantidad de trabajos dedicados al surgimiento del lenguaje ${ }^{1}$. No es posible pasar por alto el trabajo de S. I. Kartsevsky² y M. Tomasello³, sobre el origen del lenguaje humano.

Consideramos que las teorías sobre las onomatopeyas representan hipótesis sobre el origen del lenguaje, según las cuales el lenguaje surgió como consecuencia de la imitación de los sonidos de la naturaleza por parte de los seres humanos.

1 Diferentes teorías sobre la aparición del lenguaje han sido analizadas por la lingüista T. A. Nikolaieva en su trabajo "Sobre la lingüística del discurso" (2013), y también en el libro de W. T. Fitch The evolution of language (2004).

2 Kartsevsky, S. I., se interesó por las unidades mínimas de generación del discurso y su porvenir lingüístico (Kartsevsky, 2004).

3 Tomasello, M., lleva el origen del lenguaje hasta los gestos, que pasan a ser gestos-ilustraciones y gestos-situaciones, acompañados por sonidos (Tomasello, 2011). 


\subsection{Investigaciones actuales en el campo de las onomatopeyas}

En las investigaciones actuales dedicadas al problema de las onomatopeyas, se siguen diferentes corrientes. Se destacan aquí los datos científicos más significativos de este fenómeno lingüístico a juicio de los autores:

- fuentes históricas de las onomatopeyas4,

- delimitación de palabras onomatopéyicas5,

- la onomatopeya como medio de formación de nuevas palabras ${ }^{6}$,

- análisis comparativo de las onomatopeyas y de sus particularidades fonéticas?

- particularidades de la traducción de onomatopeyas ${ }^{8}$,

- diccionarios de léxico onomatopéyico?

Antes de pasar a la cuestión de la clasificación de las onomatopeyas, analizaremos su estatus lingüístico.

\subsection{Estatus lingüístico de las onomatopeyas}

La onomatopeya, a pesar de sus antiguas raíces, no ha sido lo suficientemente estudiada. A día de hoy, no hay una comprensión clara de su estatus lingüístico. Es importante señalar que las onomatopeyas se identifican a menudo con interjecciones, por ejemplo, en la Gramática académica del idioma ruso moderno de 1970 se da la siguiente definición de interjección (Gramatika sovremennogo russkovo yazyka, 1970): “Una interjección es una categoría gramatical

4 Trabajos dedicados al origen del lenguaje, relacionados con el problema de las onomatopeyas, ya mencionados en el apartado anterior, "La onomatopeya en su aspecto histórico".

5 Sobre la delimitación de las onomatopeyas y las interjecciones se tratará el siguiente apartado, "El estatus lingüístico de las onomatopeyas".

6 La capacidad de las onomatopeyas para formar palabras es objeto de investigación en diferentes idiomas. Esto se evidencia a través de artículos científicos y materiales lexicológicos. Por ejemplo, Katagoschina, 1986; Pérez y Lourdes, 1994; Rodríguez Guzmán, 2011.

7 El análisis comparativo de las onomatopeyas y sus particularidades fonéticas está presente en las investigaciones de muchos autores. Se comparan onomatopeyas de los idiomas francés, inglés, alemán español, chino y otros; por ejemplo, Casas Tost, 2008; Vozmilova y Shumkova, 2013; Sobkowiak, 1990; Grammont, 1933, 1901; Alonso-Cortés, 1999; Bernardi, 2013.

8 Las particularidades de la traducción de onomatopeyas han sido objeto de estudio en distintos idiomas; por ejemplo, Hiroko, 2009; Marquez Prieto, 2015; Lijodkina, 2015.

9 Se indica que se están llevando a cabo investigaciones lexicográficas por lingüistas de diferentes países. Se citan como ejemplos diccionarios de onomatopeyas de francés y español: Amanuma, 1974; Enckell y Rézeau, 2005; Gasca y Gubern, 2008; Hida y Hideko, 2002; Nodier, 2012. 
que designa aquellas palabras que expresan diferentes emociones y exhortaciones...”. Más adelante se habla de que junto a las interjecciones aparecen onomatopeyas (la cursiva es de los autores). Esto atestigua que no existe una definición precisa de las palabras onomatopéyicas. En la Gramática académica de 1980 (Russkaya Gramatika, 1980) se da una definición más amplia: "Una interjección es una clase de palabras inalterables que sirven para expresar sentimientos, sensaciones, estados de ánimo y otras reacciones, a menudo espontáneas, emocionales y afectivo-volitivas, ante lo que sucede a nuestro alrededor [...]. En algunos casos, junto a las interjecciones aparecen onomatopeyas"10. En artículos de autores extranjeros también se pueden seguir los intentos de definir el estatus lingüístico de las onomatopeyas ${ }^{11}$. La confusión entre los fenómenos lingüísticos de “interjección” y “onomatopeya” puede ser también observada incluso en conocidos diccionarios. Por ejemplo, en el diccionario Le Petit Larousse (PL, 2004: 511) la onomatopeya "hi-han" (que imita el rebuzno de un asno) se clasifica como interjección, aunque no es el caso. Se trata sin duda de una onomatopeya.

Los autores consideran que el léxico onomatopéyico no guarda relación con ninguna de las categorías gramaticales existentes y actúa como una palabra con categoría autónoma. A pesar de que las onomatopeyas no tienen una función gramatical nominativa, y no son una categoría gramatical como, por ejemplo, el verbo, el sustantivo, el adjetivo, el adverbio o el pronombre, poseen un significado léxico y pueden ser elementos de la oración. Se hará referencia al Diccionario enciclopédico lingüístico (bajo la dirección de Yartseva, 1990)로 y se analizará la definición de onomatopeya. Según el diccionario arriba indicado, una onomatopeya es una reproducción convencional de sonidos de la naturaleza o que acompañan algunos procesos (un temblor, una risa, un silbido, etc.) y también los sonidos emitidos por los animales. Comparando las dos definiciones -interjección y onomatopeya - no se percibió contradicción en sus estatus, con la excepción de que las onomatopeyas pueden aparecer junto a interjecciones. Cada una de estas clases de palabras cumple funciones específicas: la interjección refleja sentimientos; la onomatopeya da nombre a un objeto o fenómeno. Siguiendo a Tijonov (1981), los autores consideran que las onomatopeyas poseen un significado léxico y son palabras plenamente válidas. Para establecer una delimitación entre onomatopeyas e interjecciones, se pueden aplicar los siguientes criterios:

- pertenencia a una categoría gramatical;

- cumplimiento de funciones sintácticas;

- existencia imprescindible de contexto lingüístico (interpretación);

10 En la obra de 1980 arriba indicada, que fue reeditada, también se observa una confusión de los fenómenos lingüísticos de "interjección” y "onomatopeya”.

11 El estatus lingüístico de las onomatopeyas se analiza en el estudio de Jean-Claude Anscombre (1985) y también en el artículo de Danguole Melnikiené (2015).

12 La definición de onomatopeya en este diccionario refleja la función nominativa de estas unidades lingüísticas. 
- existencia de un significado léxico concreto;

- productividad en la formación de palabras.

Se comparan onomatopeyas e interjecciones según los criterios arriba indicados:

\section{TABLA 1}

\begin{tabular}{ccc} 
CRITERIOS & ONOMATOPEYAS & INTERJECCIONES \\
$\begin{array}{c}\text { Pertenencia a una } \\
\text { categoría gramatical }\end{array}$ & No pertenecen \\
\hline $\begin{array}{c}\text { Cumplimiento de } \\
\text { funciones sintácticas }\end{array}$ & $\begin{array}{c}\text { Pueden ser elementos } \\
\text { de la oración }\end{array}$ & Tienen categoría gramatical \\
\hline $\begin{array}{c}\text { Existencia imprescindibe } \\
\text { de contexto lingüístico } \\
\text { (interpretación) }\end{array}$ & $\begin{array}{c}\text { Indican objetos y } \\
\text { fenómenos concretos }\end{array}$ & $\begin{array}{c}\text { Van acompañados de } \\
\text { una interpretación }\end{array}$ \\
\hline $\begin{array}{c}\text { Existencia de un significado } \\
\text { léxico concreto }\end{array}$ & Lo tienen & $\begin{array}{c}\text { Requieren de aclaraciones } \\
\text { para tener significado } \\
\text { léxico concreto }\end{array}$ \\
\hline $\begin{array}{c}\text { Productividad en la } \\
\text { formación de palabras }\end{array}$ & Son productivas & No son productivas \\
\hline
\end{tabular}

La comparación de onomatopeyas e interjecciones según los criterios indicados permite considerar que las onomatopeyas actúan como clases de palabras especiales y autónomas junto a categorías gramaticales.

Los autores consideran que es posible una nueva mirada al estatus de las onomatopeyas en relación con los nuevos datos científicos sobre lingüística del discurso aportados por Nikolaieva (2015), que escribe que "la lingüística del discurso existe independientemente de la lingüística del lenguaje [...] y consiste en diversas entidades lingüísticas antiguas en origen e ignoradas [...]; las interjecciones pertenecen al fondo comunicativo de la lingüística del discurso". Se abre el poco explorado campo del estatus y del funcionamiento de las onomatopeyas en el marco de la lingüística del discurso.

\section{Resultados y discusión}

\subsection{Clasificación temática y ortográfica de las onomatopeyas}

Habiendo definido el léxico onomatopéyico como una clase autónoma de palabras, se analizan a continuación las clasificaciones existentes de onomatopeyas. En la actualidad son conocidas las clasificaciones según dos principios fundamentales: 
- Según la fuente del sonido.

- Según un principio ortográfico.

La primera clasificación ayuda a comprender la semántica de una palabra onomatopéyica cualquiera; la segunda permite guiarse por las reglas ortográficas en la transcripción de las palabras onomatopéyicas.

El trabajo más significativo para los autores es el de los lingüistas franceses Pierre Enckell y Pierre Rézeau (2005), que clasifican las onomatopeyas en los siguientes apartados:

- Sonidos del cuerpo humano; por ejemplo, el latido del corazón: toc-toc, touc-touc-touc; la risa: ha-ha-ha-hi-hi-ho-ho; ronquidos: ron-ron; un resoplido: shif-shif.

- Sonidos de animales domésticos y otros: un gallo: co-ca-ri-co; una oveja: be, me; un gato - un maullido: miau; un ronroneo: ron-ron; el sonido de sorber la leche: lap-lap; un burro: hihan; un caballo: clac-clac, clic-clac.

- Sonidos de la naturaleza: el viento: hou-hou; una rama que se rompe: crac; un trueno: craaathc.

- Sonidos de instrumentos musicales: un clarinete: tram, pam, pam; tambores: boum; sonidos de mecanismos: el timbre de un teléfono: drrr; el ruido de un tren: tatactatoum; el arranque del motor de un coche: wroumwroum.

- Sonidos de la vida cotidiana: golpes en la puerta: bambom; una botella que se vacía: glou-glou.

La clasificación de Pierre Enckell y Pierre Rézeau encuentra su fundamento en un principio temático.

La clasificación de léxico onomatopéyico basada en un principio estructural-ortográfico ayuda a la correcta transcripción de las onomatopeyas y su compresión en el texto. Esta clasificación distingue a las onomatopeyas como una palabra duplicada e incluso triplicada, que se separa con guiones: flip-flip, tac-tac-tac, tagada-tagada-tagada, incluyéndose también combinaciones rítmicas: flip-flap, flic-floc. Algunas onomatopeyas determinadas se escriben con espacio: cot cot, oua oua. Cuando la palabra está formada solo por consonantes, existen también reglas de transcripción para duplicar, triplicar o repetir muchas veces consonantes y vocales.

Teniendo en cuenta las tendencias actuales de desarrollo de las lenguas, la preferencia por la expresión, la economía de medios lingüísticos, los autores consideran que el léxico onomatopéyico se expresará como una realidad lingüística imprescindible, que requiere estudio. En relación con esto, consideran que es posible, y útil, una clasificación de las onomatopeyas desde el punto de vista de su productividad. 


\subsection{Clasificación de las onomatopeyas según su productividad}

Se sabe que cualquier clasificación se basa en principios y criterios concretos. Los autores proponen la productividad como principio, y, como criterios, los indicadores cuantitativos de las categorías gramaticales que provienen de onomatopeyas. Estas unidades de medida seleccionadas por los autores son el número de verbos, sustantivos y adjetivos. Se señala que muchas onomatopeyas forman verbos, sustantivos y adjetivos.

La hipótesis del estudio sostiene que en la lengua francesa moderna hay suficientes unidades léxicas (categorías gramaticales) provenientes de onomatopeyas, la mayoría de las cuales representan verbos y sustantivos. Se usó como método de estudio un descriptor que comprende técnicas de clasificación, observación, comparación, recapitulación e interpretación del material estudiado. El método de cuantificación se empleó para la sistematización e ilustración de los datos recibidos.

Las fuentes fundamentales del material de estudio fueron diccionarios de autores franceses (Charles Nodier, 2012, y Le Petit Larousse, 2004), y también el fichero de autores creado a partir de ejemplos de léxico onomatopéyico encontrado en producciones literarias y muestras de diferentes diccionarios. Como base del fichero de autores, se analizaron verbos, sustantivos y adjetivos provenientes de onomatopeyas y se llegó a la conclusión de que la mayor productividad de onomatopeyas se manifiesta en sustantivos y verbos. Para una mayor fiabilidad y precisión del estudio, los autores analizaron 100 unidades léxicas del diccionario de Charles Nodier ${ }^{13}$. La razón de esta muestra es que en este diccionario se explica el origen onomatopéyico de las unidades léxicas indicadas. La muestra cuantitativa fue establecida siguiendo las recomendaciones de M. Kopotev (2014), formuladas en su obra Introducción a la lingüística de corpus, donde se indica que es suficiente un texto de 5000 palabras, y un volumen mayor no cambiará el resultado lingüístico.

\section{TABLA 2}

Categorías gramaticales que provienen de onomatopeyas

\begin{tabular}{lll} 
& \multicolumn{1}{c}{ VERBO } & \multicolumn{1}{c}{ SUSTANTIVO } \\
1. aboier & 1. aboi, aboiment & 1. aboueux, aboueuse \\
\hline 2. - & 2. acheppement & 2. \\
\hline 3. - & 3. affres & 3. affreux \\
\hline
\end{tabular}

13 Los autores analizaron 150 páginas de textos de dos diccionarios —Charles Nodier, 2012, y Le Petit Larousse, 2004-, entradas del diccionario de las letras "A" y "B", lo que supuso más de 5000 palabras de texto sobre cuya base se realizó una muestra de 100 palabras onomatopéyicas (verbos, sustantivos, adjetivos). 


\begin{tabular}{|c|c|c|}
\hline 4. agacer & 4. agacement & 4. agacent(e) \\
\hline 5. agraffer & 5. agraffe & 5. - \\
\hline 6. gravir & 6. gravier & 6. - \\
\hline 7. grimper & 7. grimpette & 7. grimpant \\
\hline 8. - & 8. ame & 8. - \\
\hline 9. - & 9. anche & 9. - \\
\hline 10. - & 10. asthme & 10. asthamatique \\
\hline 11. babiller & 11. babil & 11. babillard \\
\hline 12. baller & 12. bâllement & 12. - \\
\hline 13. bayer & 13. - & 13. bée \\
\hline 14. ébanir & 14. ebanissement & 14. ébani(e) \\
\hline 15. barboter & 15. barbeteur & 15. - \\
\hline 16. - & 16. beffroi & 16. - \\
\hline 17. bêler & 17. bêlement & 17. bélant(e) \\
\hline 18. begayer & 18. bégaiment & 18. begagant(e) \\
\hline 19. beugler & 19.beuglement & 19. - \\
\hline 20. meugler & 20.meuglement & 20. - \\
\hline 21. biberonner & 21. biberon & 21. - \\
\hline 22. biffer & 22. biffage, biffement & 22. - \\
\hline 23. - & 23. bombe & 23. bombé(e) \\
\hline 24. bondir & 24. bond, bondissement & 24.- \\
\hline 25. - & 25. borborisme & $25 .^{-}$ \\
\hline 26. - & 26. bouc & 26. - \\
\hline 27. bouffer & 27. bouffer & 27. bouffant(e), bouffi(é) \\
\hline 28. - & $28 .-$ & 28. buffon, buffonne \\
\hline 29. bouiller & 29. bouillonement & 29. bouilli(é) \\
\hline 30. bouillonner & 30. bouillon & 30. bouillant(e) \\
\hline 31. - & 31. bulle & 31. - \\
\hline 32. - & 32. boule & 32. - \\
\hline 33. boutonner & 33. bouton & 33. bouteneux \\
\hline 34. bourdonner & 34. bourdennement, bourdon & 34. bourdonnant(e) \\
\hline 35. braire & 35. braiment & 35. - \\
\hline 36. bramer & 36. brame, bramement & 36. - \\
\hline
\end{tabular}




\begin{tabular}{|c|c|c|}
\hline 37. brailler & 37. braiement & 37. - \\
\hline 38. bredoiller & 38. brédouillage & $\begin{array}{l}\text { 38. brédouille, brédouilleur, } \\
\text { brédouilleuse }\end{array}$ \\
\hline 39. - & 39. brouhaha & 39. - \\
\hline 40. brouter & 40. broutement & 40.- \\
\hline 41. - & 41. broutage & 41. - \\
\hline 42. broyer & 42. broyement & 42. broyeur, broyeuse \\
\hline 43. bruire & 43. bruissement, bruit & 43. - \\
\hline
\end{tabular}

La siguiente etapa de análisis fue la búsqueda de léxico onomatopéyico (una muestra del diccionario de Charles Nodier) en el diccionario Petit Larousse 2014 para demostrar que estas unidades léxicas están vivas en el idioma francés moderno. Como resultado del análisis, los autores confirmaron la productividad de las onomatopeyas. En el siguiente diagrama se muestra la correlación cuantitativa de verbos, sustantivos y adjetivos.

\section{DIAGRAMA 1}

Correlación cuantitativa de categorías gramaticales provenientes de onomatopeyas

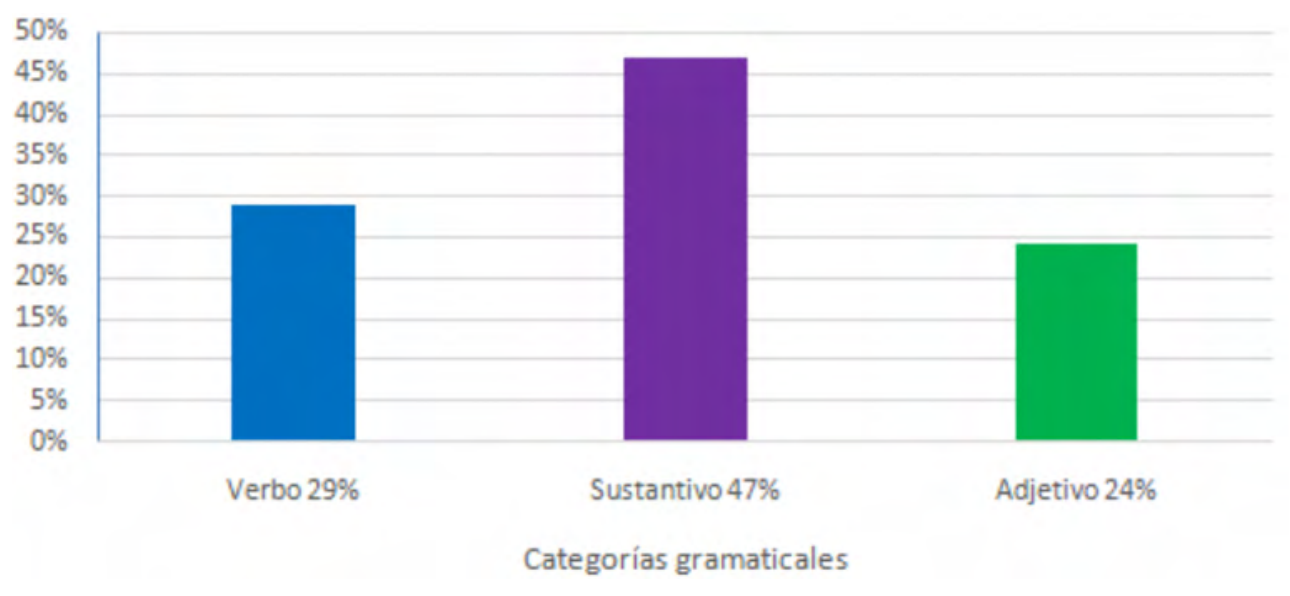

El diagrama está basado en el análisis de 100 unidades léxicas de origen onomatopéyico de las cuales el $47 \%$ son verbos; el 29\%, sustantivos, y el $24 \%$, adjetivos. El análisis cuantitativo de las categorías gramaticales provenientes de onomatopeyas permitió confirmar que la mayoría de las unidades léxicas representan sustantivos; tras ellos aparecen los verbos y los adjetivos.

También se considera de interés un análisis de las onomatopeyas desde el punto de vista de su semántica. Como han demostrado las observaciones, algunas de ellas se usan en la lengua francesa moderna solo en sentido figurado. Estos fenómenos requieren de estudios específicos. 


\subsection{Conclusiones}

La onomatopeya como fenómeno lingüístico, a pesar de sus antiguas raíces, no ha sido suficientemente estudiada. En la actualidad no hay una única opinión sobre qué representa la onomatopeya, si es un tipo de interjección, que a su vez es una categoría gramatical, o es un nivel lingüístico independiente. Los autores consideran que es razonable clasificar el léxico onomatopéyico como una categoría independiente de palabras, y recurren al argumento de la delimitación entre interjecciones y onomatopeyas.

Junto a las clasificaciones existentes según principios temáticos y ortográficos, los autores creen posible una clasificación del léxico onomatopéyico según un principio de productividad, desde el punto de vista de la capacidad de las onomatopeyas para producir nuevas palabras calificadas como categorías gramaticales ${ }^{14}$. Los autores consideran que merece atención un estudio más profundo de las onomatopeyas desde el punto de vista de su productividad en la formación de otras categorías gramaticales, y de su semántica.

\subsection{Discusión}

Como se mostró en la introducción, existen varias tendencias en el estudio de las onomatopeyas como fenómeno lingüístico. Representan un interés científico indudable los trabajos sobre los orígenes de las onomatopeyas, su análisis comparativo en diferentes lenguas, las particularidades de este tipo de palabras y de su traducción, y los diccionarios de léxico onomatopéyico.

Las investigaciones llevadas a cabo, basadas en el principio de productividad, se centran en la formación de las palabras y las cuestiones de la clasificación de léxico onomatopéyico. El estudio no contradice los datos científicos en el campo de las onomatopeyas, sino que los amplía. Los autores argumentan que debe tener lugar una delimitación entre interjección y onomatopeya, ya que su función es diferente (sobre esto versa el apartado sobre el estatus lingüístico de las onomatopeyas).

Nuestro estudio del vocabulario de corpus ha revelado una correlación cuantitativa entre categorías gramaticales formadas a partir de onomatopeyas. Los autores consideran que es posible promover este estudio para detectar la productividad de las onomatopeyas en la formación de otras categorías gramaticales, adverbios y conjunciones.

14 Los autores llevaron a cabo una investigación del léxico onomatopéyico que confirmó la productividad de las onomatopeyas en la formación de categorías gramaticales. La mayor productividad se da en la formación de sustantivos y verbos, y la menor, en la formación de adjetivos. 
Consideran asimismo prometedora una investigación en el campo de la semántica de las onomatopeyas en la lengua francesa moderna y su análisis desde el punto de vista de la lingüística del discurso.

\section{Bibliografía citada}

Alonso-CoRtés, Ángel, 1999: "Las construcciones exclamativas. La interjección y las expresiones vocativas" en Ignacio Bosque y Violeta Demonte (eds.): Gramática descriptiva de la lengua española, Madrid: Espasa-Calpe, 393-405

Amanuma, Yasushi, 1974, Giongo gitaigo jiten [Diccionario de onomatopeyas y mimesis], Tokio: Tokyo do Shuppan.

Anscombre, Jean-Claude, 1985: “Onomatopées, délocutivité et autresblablas”, Revue Romane 20 (2), 169-204.

BernARDI, Lucia, 2013: "De interjecciones, onomatopeyas y sonidos inarticulados: ¿Dónde y cómo se archiva la expresividad de la lengua? Una reflexión cognitivista”, VI Jornadas de Filología y Lingüística, 7 al 9 de agosto de 2013, La Plata, Argentina, en Memoria Académica [disponible en http://www.memoria.fahce.unlp.edu.ar/trab_eventos/ev.3841/ev.3841.pdf, fecha de consulta: 28 de noviembre de 2017].

Casas TOSt, Helena, 2008: "Estudio comparativo de las onomatopeyas chinas y españolas" en Nuevas perspectivas de investigación sobre Asia Pacífico, Barcelona, 345-360 [disponible en http://grupsderecerca.uab.cat/txicc/sites/grupsderecerca.uab.cat.txicc/files/HCT_FEIAP_estudioco mparativo_o.pdf, fecha de consulta: 28 de noviembre de 2017].

EnCKeLL, Pierre, y Pierre RéZeAu, 2005: “Dictionnaire des onomatopées”, Paris: Puf.

Fıтсн, William, 2013: La evolución del lenguaje, Moscú: Yazyki slavianskoi kultury. (Уильям Фитч, 2013: Эволюиия языка, Москва: Языки славянской культуры).

Gasca, Luis, y Roman Gubern, 2008: “Diccionario de onomatopeyas del cómic”, Madrid: Cátedra.

Gramática académica, 1980: Gramática rusa, volumen 2, bajo la dirección de Natalia SHvEdova, Moscú: Nauka, 784. (Академическая грамматика, 1980: Русская грамматика $\vee 2$, под редакцией Наталии Шведовой, Москва: Наука, 784.

Grammont, Maurice, 1901: "Onomatopées et mots expressifs", Revue des Langues Romanes 44, $97-158$

Grammont, Maurice, 1933: "La phonétique impressive” en Traité de phonétique, Paris: Libraire De la grave, 375-424. 
Gramática de la lengua rusa contemporánea, bajo la dirección de Natalia SHvedova, 1970, Moscú: Nauka, 767. (Грамматика современного русского языка, под редакцией Наталии Шведовой, 1970, Москва: Наука, 767.)

HIDA, Toshifumi, y Asada HIDEko, 2002: Gendai giongo gitaigo yoho jiten [Diccionario moderno de las onomatopeyas y las mimesis], Tokio: Tokyo do Shuppan.

HiRoko, Inose, 2009: La traducción de onomatopeyas y mímesis al español y al inglés: los casos de la novela y el manga, Granada: Universidad de Granada [disponible en digibug.ugr.es/bitstream/10481/2410/1/18193778.pdf, fecha de consulta: 28 de noviembre de 2017].

KartSEvSky, Serguei, 2004: "Introducción al estudio de las interjecciones", Cuestiones de Lingüística” 6, 127-137. (Сергей КАРцевский, 2004: “Введение в изучение междометий”, Вопросыязыкознания 6, 127-137.)

Katagoschina, Nina, 1980: Cómo se forman las palabras en la lengua francesa, Moscú: Prosveschenie, 316. (Нина КАТАГощинА, 1980: Как образуются слова во франиузском языке, Москва: Просвещение, 316.)

Kopotev, Mijail, 2014: Introducción a la lingüística de corpus, Praga: Animedia Company. (Михаил Копотев, 2014: Введение в корпусную лингвистику, Прага: AnimediaCompany.)

Le Petit Larousse, 2004, Paris: Editions Larousse, 1809.

Diccionario enciclopédico lingüístico, 1990, bajo la dirección de Viktoria YaRTSEVA, Moscú: Enciclopedia. (Лингвистический энциклопедический словарь, 1990, под редакцией Виктории Ярцевой, Москва: Энциклопедия.)

Irina LIJODKINA, 2015: "Interjecciones y onomatopeyas francesas: particularidades de su traducción (sobre la obra de R. Goscinny y J.-J. Sempé 'Les betises du petit Nicolas' y sus traducciones a ruso e italiano)", Ciencias Filológicas. Cuestiones de Teoría y Práctica (Tambov: Gramota) 10-2 (2), 121-124. (Ирина ЛиходкинА, 2015: “Французские междометия и звукоподражания, особенности их перевода (на материале произведения Р. Госинни, Ж.-Ж. Семпе 'Les betises du petit Nicolas' и его переводов на русский и итальянские языки)", Филологические науки. Bопросы теории и практики (Тамбов: Грамота) 10-2 (2), 121-124.)

Marquez Prieto, Cristina, 2015: La onomatopeya y sutraducción, Barcelona: Universitat de Pompeu Fabra [disponible en https://repositori.upf.edu/bitstream/handle/10230/27831/Marquez_2016.pdf?sequence=1, fecha de consulta: 28 de noviembre de 2017].

MelNIKIEnÉ, Dangoulé, 2015: "Le status grammatical des onomatopées dans la linguistique moderne”, Verbum 6, 168-186.

Nikolaieva, Tatiana, 2015: "Sobre 'la lingüística del discurso' (en particular sobre las interjecciones)", Cuestiones de Lingüística (Moscú: Nauka) 4, 7-20. (Татьяна Николаева, 2015: “О 'лингвистике речи' (в частности о междометии)”, Вопросы языкознания (Москва: Наука) 4, 7- 20.) 
Nodier, Charles, 2012: Dictionnaire raisonné des onomatopées françaises, Paris: Hachette.

PéREz, Bueno, y Maria LouRDES, 1994: "La onomatopeya y su proceso de lexicalización: notas para un estudio", Anuario de Estudios Filológicos 17, 15-26 [disponible en https://dialnet.unirioja. es/servlet/articulo?codigo=58804, fecha de consulta: 28 de noviembre de 2017].

Rodriguez Guzmán, Jorge, 2011: "Morfología de la onomatopeya. ¿Subclase de palabra subordinada a la interjección?” Moenia 17, 125-178 [disponible en https://minerva.usc.es/xmlui/bitstream/handle/10347/7330/5-Rodr\%EDguez\%20Guzm\%E1n.pdf;jsessionid=DCD4B6FBE4C960F 059A41F76605B5D4B?sequence=1, fecha de consulta: 28 de noviembre de 2017].

SoвкоwIAK, Wlodzimier, 1990: "On the phonostatitics on English onomatopoeia", Studia Anglica Posnaniensia 23, 15-30 [disponible en https://repozytorium.amu.edu.pl/bitstream/10593/179 90/1/02Sobkowiak.pdf, fecha de consulta: 28 de noviembre de 2017].

Tiıonov, Aleksandr, 1981: "Interjecciones y palabras onomatopéyicas", Russkaya Rech (Moscú: Nauka) 5, 72-76. (Александр ТИХОНОВ, 1981: "Междометия и звукоподражательные слова", Русская речь (Москва: Наука) 5, 72-76.)

Tomasello, Michael, 2011: Origins of human communication, Moscú: Yazyki slavianskij kultur. (Майкл ТОМАСЕЛЛО, 2011: Истоки человеческого общения, Москва: Языки славянских культур.)

Vozmılova, Irina, y Yulia Shumkova, 2013: Similitudes y diferencias de las onomatopeyas en distintos idiomas, Ekaterimburgo: Universidad Federal de los Urales. (Ирина ВОЗМИЛОВА \& Юлия ШУМКОВА, 2013: Сходства и различия ономатопов в разных языках, Екатеринбург: Уральский Федеральный Университет.) 